\title{
Antimicrobial and Anti-Adhesive Potential of a Biosurfactants Produced by Candida Species
}

\author{
Raquel Diniz Rufino, Juliana Moura de Luna, Leonie Asfora Sarubbo, \\ Lígia Raquel Marona Rodrigues, José Antônio C. Teixeira \\ and Galba Maria de Campos-Takaki
}

Additional information is available at the end of the chapter

http://dx.doi.org/10.5772/52578

\section{Introduction}

Several compounds with tensioactive properties are synthesized by living organisms, from plants (e.g. saponins) to microorganisms (e.g. glycolipids) and humans (e.g. surface-active lipoprotein complex), being considered natural surfactants [1]. Additionally, these compounds have been produced through biotechnological processes broadening their diversity and potential applications [2]. Surfactants are usually organic compounds that are amphiphilic, meaning they contain both hydrophobic groups (tails) and hydrophilic groups (heads), and that act preferably in the interface of fluid phases with different levels of polarity and bridges of hydrogen, such as oil/water or air/water interfaces. Many microbes appear to produce a complex mixture of biosurfactants, particularly during their stationary growth on water-immiscible substrates. Generally, biosurfactants are secondary metabolites with the typical amphiphilic structure of a surfactant, where the hydrophobic moiety is either a long-chain fatty-acid, hydroxyl fatty acid, or $\alpha$-alkyl- $\beta$-hydroxy fatty acid and the hydrophilic moiety can be a carbohydrate, an amino acid, a cyclic peptide, a phosphate, a carboxylic acid, or alcohol, among others [1].

Physical and chemical properties, surface tension reduction, and stability of the emulsion formed are important characteristics in biosurfactant that make possible its use in countless biological applications. Most work on biosurfactant applications has been focused on their use in environmental applications owing to their diversity, environmentally friendly nature, suitability for large-scale production and selectivity [3]. Biosurfactants have several advantages over chemical surfactants, such as lower toxicity, higher biodegradability and effectiveness at extreme temperatures or $\mathrm{pH}$ values [4]. Many of the potential applications that have been considered for biosurfactants depend on whether they can be produced 
economically; however, much effort in process optimization and at the engineering and biological levels have been carried out [5]. Despite their potential and biological origin only a few studies have been carried out on applications related to the biomedical field [6]. Some biosurfactants are suitable alternatives to synthetic medicines and antimicrobial agents and may be used as safe and effective therapeutic agents [6].

Furthermore, biosurfactants have been found to inhibit the adhesion of pathogenic organisms to solid surfaces or to infection sites hampering biofilm formation that is the cause of many diseases, as for example cystic fibrosis [7]. Therefore, prior adhesion of biosurfactants to solid surfaces might constitute a new and effective means of combating colonization by pathogenic microorganisms and subsequent biofilm formation $[8,9]$.

Pre-coating vinyl urethral catheters by running a surfactin solution through them before inoculation with media resulted in a decrease in the amount of biofilm formed by Salmonella typhimurium, S. enterica, Escherichia coli and Proteus mirabilis [10]. Given the importance of opportunistic infections with Salmonella species, including urinary tract infections of AIDS patients, these results have great potential for practical applications. In addition, the use of lactobacilli as a probiotic for the prevention of urogenital infections has been widely studied [11].

Microbial surfactants are not yet competitive with those produced by the chemical industry, but efforts should be made on the different production aspects to find suitable and economic substrates and to develop new strategies to increase the volumetric productivity. We have shown that the co-utilization of ground-nut oil refinery residue and corn steep liquor is an attractive choice for biosurfactant production. The biosurfactant adhesive mechanism is based in the inhibition of microorganisms to different surfaces can interact with interfaces of the molecule. In this sense, they are an alternative to synthetic surface-active agents because of their low toxicity and biodegradability $[7,12]$.

Considering the lack of studies with yeasts biosurfactants for medical purposes, and is an attractive characteristics showed by produced by the Candida lipolytica (Rufisan) and Candida sphaerica (Lunasan). In this sense the revision shown the role and applications of rufisan and lunasan biosurfactant as a antimicrobial and antiadhesive activities were investigated against pathogenic and nonpathogenic microorganisms, and indicated the therapeutic perspectives.. Results gathered in the current work showed the potential of those molecules in this field of application; however, its use still remains limited, possibly as due to high production costs, as well as on their toxicity towards human systems.

\section{Adhesion and microbial biofilms}

The interest of biosurfactants as alternative medicines and antimicrobial agents increased considering the safe use as effective therapeutic agent on human and animal cells [12]. In consequence, the microbial adhesion is mediated by specific interactions between cells surface structures and molecular mass on the substratum surface, or by non-specific interaction forces, including electrostatic forces, acid-base interactions and Vander Waals forces [13]. 
during exponential growth, presumably as a result of increased cell wall hydrophobicity during this growth phase

The conditioning film on the biomaterial surface (and on the bacterial cell surface) plays an important role, as it changes the physicochemical properties of the interacting surfaces. Albumin is a strong adhesion inhibitor, for unknown reasons, although changes in hydrophobiciy and sterical hindrance are proposed as mechanisms [14].

The adhesion of microorganisms to a surface is one of the first stages in the development of a biofilm and is believed to be influenced by a number of factors. As the substrate is essential in the development of a biofilm, an understanding of how substrate properties affected the adherence of bacterial cells my assist in designing or modifying substrates inhibitory to bacterial adhesion. Many of these molecules are proteinaceous constitution, such as serum albumin, fibrogen and collagen, and some have been shown to affect subsequent bacterial adhesion [13].

The formation of infectious biofilm on biomaterial appeared to involve several sequential steps. Immediately after exposure of a device to body fluids, such as blood, saliva, or urine, macromolecular components adsorb to form a conditioning film [15]. The most microbial surfactants are complex molecules, comprising different structures that include peptides, glycolipids, glycopeptides, fatty acids and phospolipids, as reviewed recently. Among the many classes of biosurfactants, lipopeptides are particularly interesting because their high surface activities and antibiotic potential. Lipopeptides are molecules act as antibiotics, antiviral and antitumoral agents, and enzyme inhibitors. Those molecules enhance or decrease the bacterial surface hydrophobicity following that the surface is less or more hydrophobic[16]. Morikawa et al. [17] identified and characterized a biosurfactant, arthrofactin, produced by Arthrobacter.

Glycolipids are the most common class of biosurfactans of which the most effective from the point of view of surface active properties arethe trehalose lipids of Mycobacterium and related bacteria, the rhamnolipids of Pseudomonas sp and the sophorolipids of yeasts [18]. Otto et al. [19] described the production of sophorose lipids from deproteinized whey concentrate by a two-stage process. Several antimicrobial, immunological and neurological properties have been attributed to mannosylerythritol lipid (MEL), a yeast glycolipid biosurfactant, produced from vegetable oils by Candida strains.

\section{Antimicrobial activity of biosurfactant}

Several biosurfactants which exhibit antimicrobial activity against various microorganisms have been previously described. They include surfactin and iturin produced by Bacillus subtilis strains [20], rhamnolipids from Pseudomonas species [21], mannosylerythritol lipids from C. antarctica [22] and biosurfactants produced by some fungi [23].

Among the genus Bacillus, B. subtilis produces a broad spectrum of bioactive lipopeptides which have a great potential for biotechnological and biopharmaceutical applications. The 
characteristic structure of lipopeptides is a fatty acid combined with an amino-acid moiety. Several lipopeptides have potent antibiotic activity and have been the subject of several studies on the discovery of new antibiotics. The list includes surfactin, produced by $B$. subtilis, the most powerful of biosurfactant known to date. These compounds have many pharmacological activities: antibacterial, antifungal, antiviral, and antimycoplasma properties; inhibition of the fibrin clot formation and hemolysis; formation of ion channels in lipid bilayer membranes [24]; antitumour activity against Ehrlich's ascites carcinoma cells; and inhibition of the cyclic adenosine 3,5-monophosphate phosphodiesterase [25].

The evaluation of the antimicrobial activity of these compounds was carried out against 29 bacteria. Enterococcus faecalis (11 strains), Staphylococcus aureus (6 strains) and Pseudomonas aeruginosa (7 strains) and Escherichia coli CI 18 (1 strain) displayed a profile of well defined drug resistance. All strains were sensitive to the surfactants, in particular Enterococcus faecalis. The results demonstrated that lipopeptides have a broad spectrum ofaction, including antimicrobial activity against microorganisms with multidrug-resistant profiles [26].

The antimicrobial activity of the crude biosurfactant isolated from Candida lipolytica UCP 0988 was determined by measuring the growth inhibition percentages obtained for several microorganisms (Table 1).

\begin{tabular}{lccccc}
\hline \multirow{2}{*}{ Microorganism } & \multicolumn{5}{c}{ Growth inhibition (\%) } \\
\cline { 2 - 6 } & 0.75 & 1.5 & 3.0 & 6.0 & 12.0 \\
\hline Lactobacillus casei & $4.5 \pm 0.02$ & $9.1 \pm 0.07$ & $15 \pm 0.02$ & $27.2 \pm 0.08$ & $28.4 \pm 0.05$ \\
Lactobacillus casej72 & $4.5 \pm 0.03$ & $14.2 \pm 0.08$ & $18.1 \pm 0.06$ & $32.9 \pm 0.06$ & $33.7 \pm 0.03$ \\
Lactobacillus reuteri 104R & $5.9 \pm 0.07$ & $9.7 \pm 0.01$ & $15.5 \pm 0.01$ & $24.4 \pm 0.05$ & $25.4 \pm 0.08$ \\
Lactobacillus reuteri ML1 & $8.2 \pm 0.06$ & $11.3 \pm 0.02$ & $16.3 \pm 0.02$ & $31.1 \pm 0.02$ & $32.1 \pm 0.02$ \\
Escherichia coli & 0 & 0 & $3.0 \pm 0.01$ & $5.0 \pm 0.01$ & $5.0 \pm 0.01$ \\
Streptococcus agalactiae & 0 & $10.9 \pm 0.03$ & $35.3 \pm 0.03$ & $35.8 \pm 0.02$ & $35.5 \pm 0.02$ \\
Streptococcus mutans NS & $15.6 \pm 0.07$ & $20.1 \pm 0.04$ & $23.8 \pm 0.13$ & $46.0 \pm 0.1$ & $46.4 \pm 0.01$ \\
Streptococcus sanguis 12 & $13.7 \pm 0.07$ & $21.5 \pm 0.04$ & $31.7 \pm 0.05$ & $48.1 \pm 0.08$ & $48.0 \pm 0.01$ \\
Streptococcus mutans. & $22.5 \pm 0.02$ & $34.8 \pm 0.01$ & $44.6 \pm 0.01$ & $58.3 \pm 0.01$ & $58.0 \pm 0.06$ \\
Streptococcus oralis J22 & $12.8 \pm 0.04$ & $13.2 \pm 0.03$ & $14.2 \pm 0.03$ & $18.7 \pm 0.08$ & $62.8 \pm 0.06$ \\
Streptococcus mutans HG985 & $41.8 \pm 0.02$ & $43.1 \pm 0.01$ & 55.60 .04 & $64.6 \pm 0.03$ & $64.9 \pm 0.01$ \\
Pseudomonas aeruginosa & 0 & $7.9 \pm 0.02$ & $10 \pm 0.01$ & $11.6 \pm 0.01$ & $16.5 \pm 0.04$ \\
Staphylococcus aureus & 0 & 0 & $1.57 \pm 0.06$ & $3.15 \pm 0.06$ & $15.1 \pm 0.03$ \\
Staphylococcus epidermidis & $10.1 \pm 0.01$ & $12.9 \pm 0.07$ & $14.9 \pm 0.07$ & $18.1 \pm 0.01$ & $18.0 \pm 0.06$ \\
Candida albicans & 0 & 0 & $3.1 \pm 0.03$ & $5.95 \pm 0.01$ & $6.0 \pm 0.02$ \\
\hline
\end{tabular}

Table 1. Percentages of growth inhibition obtained with the biosurfactant Rufisan isolated from Candida lipolytica at different concentrations ( $\mathrm{mg} / \mathrm{l})$. Results are expressed as means \pm standard deviations of values obtained from triplicate experiments

The biosurfactant was effective against the microorganisms tested, albeit to different degrees. The highest anti-adhesive percentages were obtained for a biosurfactant 
concentration of $12 \mathrm{mg} / \mathrm{l}$ or $4 \times \mathrm{CMC}$. Non-pathogenic species associated with the oral cavity of Streptococcus were used (S. mutans HG $-64.9 \%$; S. oralis J22 $-62.8 \%$; S. mutans $-58 \%$; S. sanguis $12-48 \%$; S. mutans NS -46\%). On the other hand, the biosurfactant did not show an effective antimicrobial activity against the Lactobacillus strains studied. It inhibited only $32.1 \%$ of the growth of $L$. reuteri ML1 at the maximum concentration tested (12 mg/l).

The growth of the other microorganisms tested was poorly inhibited. Percentages of $5 \%, 5 \%$, $15 \%, 16 \%$ and $18 \%$ were observed for C. albicans, E. coli, S. aureus, P. aeruginosa and S. epidermidis, respectively.

The antimicrobial activity of the biosurfactant isolated from Candida sphaerica was determined by measuring the growth inhibition percentages obtained for several microorganisms (Table 2).

\begin{tabular}{|c|c|c|c|c|c|}
\hline \multirow[b]{2}{*}{ Microorganism } & \multicolumn{5}{|c|}{ Growth inhibition (\%) } \\
\hline & 0.625 & 1.25 & $\begin{array}{l}\text { urfactant } \mathrm{mg} / \mathrm{L} \\
2.5\end{array}$ & 5.0 & 10.0 \\
\hline Lactobacillus casej & $5.5 \pm 0.2$ & $12.0 \pm 0.3$ & $15.0 \pm 0.1$ & $30.0 \pm 0.4$ & $40.4 \pm 0.2$ \\
\hline Lactobacillus casej72 & $5.5 \pm 0.3$ & $11.0 \pm 0.2$ & $13.0 \pm 0.4$ & $25.0 \pm 0.3$ & $43.3 \pm 0.1$ \\
\hline Lactobacillus reuteri 104R & $10.0 \pm 0.1$ & $17.3 \pm 0.3$ & $22.0 \pm 0.5$ & $4.40 \pm 0.3$ & $46.5 \pm 0.1$ \\
\hline Lactobacillus reuteri ML1 & $8.5 \pm 0.3$ & $11.0 \pm 0.2$ & $16.0 \pm 0.2$ & $27.0 \pm 0.2$ & $49.0 \pm 0.2$ \\
\hline Escherichia coli & $7.3 \pm 0.2$ & $10.0 \pm 0.3$ & $11.0 \pm 0.3$ & $35.0 \pm 0.2$ & $46.0 \pm 0.2$ \\
\hline Streptococcus agalactiae & $14.0 \pm 0.1$ & $17.8 \pm 0.1$ & $22.6 \pm 0.1$ & $38.3 \pm 0.1$ & $40.2 \pm 0.6$ \\
\hline Streptococcus mutans NS & $14.2 \pm 0.3$ & $15.6 \pm 0.4$ & $20.0 \pm 0.3$ & $23.8 \pm 0.1$ & $36.0 \pm 0.1$ \\
\hline Streptococcus sanguis 12 & $22 \pm 0.2$ & $33.1 \pm 0.1$ & $45.6 \pm 0.3$ & $46.0 \pm 0.4$ & $48.0 \pm 0.1$ \\
\hline Streptococcus mutans & $10.3 \pm 0.6$ & $15.4 \pm 0.1$ & $28.0 \pm 0.1$ & $32.2 \pm 0.5$ & $42.5 \pm 0.2$ \\
\hline Streptococcus oralis J22 & $13.6 \pm 0.3$ & $15.0 \pm 0.4$ & $15.5 \pm 0.5$ & $28.0 \pm 0.8$ & $39.0 \pm 0.1$ \\
\hline Streptococcus mutans HG985 & $11.0 \pm 0.4$ & $13.2 \pm 0.3$ & $15.2 \pm 0.3$ & $30.7 \pm 0.4$ & $68.0 \pm 0.2$ \\
\hline Pseudomonas aeruginosa & $8.3 \pm 0.1$ & $13.5 \pm 0.2$ & $25.0 \pm 0.2$ & $42.0 \pm 0.1$ & $57.6 \pm 0.3$ \\
\hline Staphylococcus aureus & $10.6 \pm 0.1$ & $20.0 \pm 0.2$ & $27.3 \pm 0.3$ & $32.2 \pm 0.2$ & $43.9 \pm 0.1$ \\
\hline Staphylococcus epidermidis. & $7.7 \pm 0.1$ & $8.0 \pm 0.1$ & $12.5 \pm 0.1$ & $13.6 \pm 0.4$ & $47.0 \pm 0.2$ \\
\hline Candida albicans & $12.5 \pm 0.2$ & $17.3 \pm 0.3$ & $32.0 \pm 0.3$ & $44.2 \pm 0.1$ & $57.0 \pm 0.2$ \\
\hline
\end{tabular}

Table 2. Percentages of growth inhibition obtained with the crude biosurfactant Lunasan isolated from Candida sphaerica at different concentrations ( $\mathrm{mg} / \mathrm{l})$. Results are expressed as means \pm standard deviations of values obtained from triplicate experiments

The tested biosurfactant presented antimicrobial activity against all microorganisms used, although, depending on the microorganism, the biosurfactant presents different effective concentrations. The highest concentration of biosurfactant tested $\left(10 \mathrm{mg} \mathrm{ml}^{-1}\right)$ showed high percentages of inhibition for Streptococcus oralis J22 (68\%), C. albicans (57\%) and Staphylococcus epidermidis (57.6\%). The antimicrobial activity of the crude biosurfactant isolated from Candida sphaerica with concentrations between 5 and $10 \mathrm{mg} \mathrm{ml}^{1}$ against $C$. albicans, Staph. aureus and Staph. epidermidis was less to that obtained with the biosurfactants 
isolated from Lact. paracasei ssp A20, which completely inhibited the growth of those microrganisms with concentrations between 25 and $50 \mathrm{mg} \mathrm{ml}^{-1}$ ) [27] .

The crude biosurfactant showed antimicrobial activity against a broad range of microorganisms, including Gram-positive and Gram-negative bacteria and yeasts.

Biosurfactants antimicrobial activity has been described, as for example surfactin, a cyclic lipopeptide produced by Bacillus subtilis [28]. The antimicrobial activity of surfactin was tested against several microbes. All tested bacteria, except for B. subtilis, showed susceptibility to surfactin. P. aeruginosa was the most sensitive Gram-negative bacteria, while E. coli, Salmonella choterasius and Serratia marcescens were inhibited in a lower level. Also, the lipopeptide affected the growth of Gram-positive bacteria, especially Micrococcus luteus and Bacillus cereus [18]. Other examples have been reported by Rodrigues and coworkers [8, 27]. Crude biosurfactants isolated from Lactococcus lactis 53 and Streptococcus thermophilus A showed antimicrobial activity against C. troplicalis GB in low concentrations.

Some biosurfactants are able, even in low concentrations, to destabilize the microorganism's membranes, killing them or disabling their growth $[29,30]$. The interest in biosurfactants was first expressed due to its potential antimicrobial properties, being the first reported and actually the most studied biosurfactants, rhamnolipid and surfactin [31]. Gram-positive bacteria are more sensitive to biosurfactants than Gram-negative bacteria, which are weakly inhibited or not inhibited at all [32]. C. bombicola and C. apicola were reported to produce a glycolipid-type biosurfactant (sophorolipid) that inhibit the growth of B. subtilis, S. epidermidis and Streptococcus faecium in concentrations between 6 and $29 \mathrm{mg} / \mathrm{l}$ [33]. Other glycolipids inhibit not only the growth of Gram-positive bacteria, but also Gram-negative ones, such as E. coli and S. marcescens [31]. Kitamoto et al. [34] reported in their work an antimicrobial activity against S. aureus, E. coli, P. aeruginosa and C. albicans for a mannosylerythritol roduced by $C$. antarctica, a sophorolipid produced by $C$. apicola and a rhamnolipid produced by P. aeruginosa.

Several biosurfactants that exhibit antimicrobial activity have been previously described. However, there are few reports about the antimicrobial activity of biosurfactants isolated from Candida; only biosurfactants obtained from S. thermophilus A and L. lactis 53 showed significant antimicrobial activity against several bacterial and yeast strains isolated from explanted voice prostheses [35].

\section{Anti-adhesive activity of biosurfactant}

Involvement of biosurfactants in microbial adhesion and desorption has been widely described, and adsorption of biosurfactants to solid surfaces might constitute an effective strategy to reduce microbial adhesion and combating colonization by pathogenic microorganisms, not only in the biomedical field, but also in other areas, such as the food industry $[36,37]$. 
Biosurfactants have been found to inhibit the adhesion of pathogenic organisms to solid surfacesor to infection sites, thus prior adhesion of biosurfactant to solid surfaces might constitute a new and effective means of combating colonization by pathogenic microorganisms [12]. Precoating vinyl urethral catheters by running a surfactin solution through them before inoculation with media resulted in a decrease of the amount of biofilm formed by Salmonella typhimurium, Salmonella enteric, Escherichia coli and Proteus mirabilis [38]. Given the importance of opportunistic infections with Salmonella species, including urinary tract infections of AIDS patients, these results have great potential for practical applications.

In addition to the antimicrobial properties, the anti-adhesive activity of the biosurfactant was evaluated against a variety of bacterial and fungal strains. The biosurfactant showed anti-adhesive activity against most of the microorganisms tested, but the anti-adhesive effect depends on the concentration and the micro-organism tested (Table 3).

\begin{tabular}{|c|c|c|c|c|c|c|}
\hline \multirow{2}{*}{ Microorganism } & \multicolumn{6}{|c|}{ Anti-adhesive activity (\%) } \\
\hline & 0.75 & 1.5 & $\begin{array}{l}\text { Biosurf } \\
3.0\end{array}$ & $\begin{array}{c}\mathrm{mg} / \mathrm{L} \\
6.0\end{array}$ & 12.0 & $\begin{array}{c}\text { PBS } \\
\text { (control) }\end{array}$ \\
\hline Lactobacillus casei & $91 \pm 0.1$ & $91 \pm 0.1$ & $99 \pm 0.1$ & $99 \pm 0.1$ & $99 \pm 0.1$ & Q \\
\hline Lactobacillus casei72 & $81 \pm 0.0$ & $87 \pm 0.0$ & $89 \pm 0.0$ & $91 \pm 0.0$ & $95 \pm 0.0$ & Q \\
\hline Lactobacillus reuteri $104 \mathrm{R}$ & $84 \pm 0.2$ & $93 \pm 0.2$ & $94 \pm 0.2$ & $95 \pm 0.2$ & $97 \pm 0.2$ & Q \\
\hline Lactobacillus reuteri ML1 & $81 \pm 0.0$ & $82 \pm 0.0$ & $84 \pm 0.0$ & $87 \pm 0.0$ & $89 \pm 0.0$ & Q \\
\hline Escherichia coli & $8 \pm 0.1$ & $17 \pm 0.1$ & $18 \pm 0.1$ & $25 \pm 0.1$ & $27 \pm 0.1$ & Q \\
\hline Streptococcus agalactiae & $80 \pm 0.0$ & $81 \pm 0.0$ & $81 \pm 0.0$ & $84 \pm 0.0$ & $96 \pm 0.0$ & Q \\
\hline Streptococcus mutans NS & $91 \pm 0.1$ & $95 \pm 0.1$ & $96 \pm 0.1$ & $98 \pm 0.1$ & $99 \pm 0.1$ & Q \\
\hline Streptococcus sanguis 12 & $61 \pm 0.0$ & $62 \pm 0.0$ & $68 \pm 0.0$ & $70 \pm 0.0$ & $77 \pm 0.0$ & Q \\
\hline Streptococcus mutans. & $76 \pm 0.1$ & $84 \pm 0.1$ & $85 \pm 0.1$ & $88 \pm 0.1$ & $97 \pm 0.1$ & Q \\
\hline Streptococcus oralis J22 & $73 \pm 0.0$ & $85 \pm 0.0$ & $87 \pm 0.0$ & $89 \pm 0.0$ & $90 \pm 0.0$ & Q \\
\hline Streptococcus mutans HG985 & $76 \pm 0.1$ & $76 \pm 0.1$ & $81 \pm 0.1$ & $83 \pm 0.1$ & $85 \pm 0.1$ & Q \\
\hline Pseudomonas aeruginosa & $13 \pm 0.0$ & $26 \pm 0.0$ & $33 \pm 0.0$ & $41 \pm 0.0$ & $49 \pm 0.0$ & Q \\
\hline Staphylococcus aureus & $88 \pm 0.0$ & $91 \pm 0.0$ & $92 \pm 0.0$ & $97 \pm 0.0$ & $98 \pm 0.0$ & Q \\
\hline Staphylococcus epidermidis & $2 \pm 0.0$ & $5 \pm 0.0$ & $6 \pm 0.0$ & $16 \pm 0.0$ & $21 \pm 0.0$ & Q \\
\hline Candida albicans & $8 \pm 0.0$ & $8 \pm 0.0$ & $16 \pm 0.0$ & $36 \pm 0.0$ & $51 \pm 0.0$ & Q \\
\hline
\end{tabular}

Table 3. Anti-adhesive properties of crude biosurfactant isolated from Candida lipolytica. Negative controls were set at $0 \%$ to indicate the absence of biosurfactant. Positive percentages indicate the reductions in microbial adhesion when compared to the control. Results are expressed as means \pm standard deviation of results from triplicate experiments

The crude biosurfactant showed anti-adhesive activity against most of the microorganisms tested from the minimum concentration used $(0.75 \mathrm{mg} / \mathrm{l})$. The anti-adhesive property was proportional to the concentration of the biosurfactant. For the microorganisms of the Lactobacillus anti-adhesive values around $81 \%$ were observed at the minor concentration tested $(0.75 \mathrm{mg} / \mathrm{l})$. The major anti-adhesive specificity was observed against $L$. casei with 
values of $91 \%$ and $99 \%$ with the minimum concentration used. Low inhibitions were observed for S. epidermidis and E. coli, with values of $27 \%$ and $21 \%$, respectively, at the maximum biosurfactant concentration. For the other microorganisms, the anti-adhesive activity was above $45 \%$.

Gudina et al. [24] observed an anti-adhesive activity for the biosurfactant from Lactobacillus paracasei against several pathogenic microorganisms such as S. aureus, S. epidermidis and $S$. agalactiae. However, this biosurfactant showed low anti-adhesive activity against $E$. coli, $C$. albicans and $P$. aeruginosa, in contrast with the antimicrobial activity exhibited against these strains at the same biosurfactant concentrations.

The use and potential commercial applications of biosurfactants in the medical field has increased considerably in the last years. Their antimicrobial and anti-adhesive properties make them relevant molecules for use in combating many diseases and infections and as therapeutic agents [18].

\begin{tabular}{|c|c|c|c|c|c|}
\hline \multirow{3}{*}{ Microorganism } & \multicolumn{5}{|c|}{ Anti-adhesive activity (\%) } \\
\hline & \multicolumn{4}{|c|}{ Biosurfactant mg/L } & \multirow{2}{*}{10.0} \\
\hline & 0.625 & 1.25 & 2.5 & 5.0 & \\
\hline Lactobacillus casej & $53 \pm 0.1$ & $53 \pm 0.2$ & $56 \pm 0.1$ & $67 \pm 0.3$ & $90 \pm 0.2$ \\
\hline Lactobacillus casej72 & $59 \pm 0.3$ & $61 \pm 0.2$ & $65 \pm 0.4$ & $70 \pm 0.2$ & $72 \pm 0.1$ \\
\hline Lactobacillus reuteri 104R & $41 \pm 0.1$ & $42 \pm 0.1$ & $45 \pm 0.4$ & $50 \pm 0.2$ & $55 \pm 0.1$ \\
\hline Lactobacillus reuteri ML1 & $26 \pm 0.2$ & $28 \pm 0.1$ & $30 \pm 0.3$ & $34 \pm 0.2$ & $40 \pm 0.2$ \\
\hline Streptococcus agalactiae & $80 \pm 0.1$ & $86 \pm 0.2$ & $88 \pm 0.2$ & $92 \pm 0.3$ & $100 \pm 0.2$ \\
\hline Streptococcus mutans. & $58 \pm 0.1$ & $64 \pm 0.1$ & $67 \pm 0.1$ & $80 \pm 0.2$ & $100 \pm 0.1$ \\
\hline Streptococcus mutans NS & $60 \pm 0.3$ & $65 \pm 0.2$ & $68 \pm 0.2$ & $80 \pm 0.3$ & $100 \pm 0.2$ \\
\hline Streptococcus mutans HG & $41 \pm 0.2$ & $42 \pm 0.1$ & $44 \pm 0.2$ & $47 \pm 0.2$ & $50 \pm 0.1$ \\
\hline Streptococcus pyogenes & $33 \pm 0.3$ & $40 \pm 0.1$ & $42 \pm 0.1$ & $47 \pm 0.5$ & $49 \pm 0.2$ \\
\hline Streptococcus sanguis 12 & $80 \pm 0.3$ & $83 \pm 0.4$ & $87 \pm 0.1$ & $98 \pm 0.2$ & $100 \pm 0.1$ \\
\hline Streptococcus oralis J22 & $77 \pm 0.1$ & $84 \pm 0.1$ & $88 \pm 0.3$ & $95 \pm 0.4$ & $97 \pm 0.2$ \\
\hline Streptococcus salivarius & $92 \pm 0.4$ & $93 \pm 0.2$ & $95 \pm 0.4$ & $97 \pm 0.4$ & $100 \pm 0.2$ \\
\hline Staphylococcus epidermidis. & $11 \pm 0.1$ & $12 \pm 0.1$ & $13 \pm 0.2$ & $19 \pm 0.1$ & $22 \pm 0.3$ \\
\hline Staphylococcus aureus & $75 \pm 0.2$ & $82 \pm 0.3$ & $85 \pm 0.3$ & $90 \pm 0.2$ & $92 \pm 0.1$ \\
\hline Echerichia coli & $89 \pm 0.4$ & $93 \pm 0.2$ & $96 \pm 0.1$ & $97 \pm 0.2$ & $99 \pm 0.2$ \\
\hline Pseudomonas aeruginosa & $80 \pm 0.2$ & $82 \pm 0.1$ & $83 \pm 0.3$ & $89 \pm 0.2$ & $92 \pm 0.2$ \\
\hline Candida albicans & $52 \pm 0.3$ & $56 \pm 0.2$ & $57 \pm 0.1$ & $64 \pm 0.2$ & $71 \pm 0.2$ \\
\hline Candida tropicallis & $80 \pm 0.3$ & $85 \pm 0.2$ & $87 \pm 0.1$ & $98 \pm 0.3$ & $100 \pm 0.1$ \\
\hline Rothia dentocariosa & $55 \pm 0.3$ & $57 \pm 0.2$ & $60 \pm 0.4$ & $68 \pm 0.3$ & $72 \pm 0.2$ \\
\hline
\end{tabular}

Table 4. Anti-adhesive properties of crude biosurfactant isolated from Candida sphaerica. Negative controls were set at $0 \%$ to indicate the absence of biosurfactant. Positive percentages indicate the reductions in microbial adhesion when compared to the control

Adhesion to surfaces and subsequent biofilm formation consist in a surviving strategy used by microorganisms in several hostile environments, protecting them from dehydration, 
predators, biocides and extreme conditions [22]. The antiadhesive activity of this biosurfactant was evaluated against a variety of bacterial and fungal strains. The biosurfactant showed antiadhesive activity against most of the microrganisms tested, but the antiadhesive effect depends on the concentration and the microrganism tested (Table 4).

This biosurfactant was effective against all the microorganisms tested, albeit to different degree. With regard to the Lactobacillus strains, the antiadhesive activity was higher against Lact. casei (90\%), Lact. casei 72 (72\%), Lact. reuteri 104R (55\%) and Lact. reuteri ML1 (40\%). For the pathogenic bacteria studied (Streptococcus agalactiae, Streptococcus mutans, Streptococcus mutans NS, Streptococcus sanguis 12, Streptococcus salivarius GB and Echerichia coli), a complete inhibition of adhesion was also achieved with biosurfactant concentrations of $10 \mathrm{mg} \mathrm{ml}^{-1}$.

Regarding the yeast, a total inhibition of adhesion was also observed for C. tropicalis GB at a biosurfactant concentration of $10 \mathrm{mg} \mathrm{ml}^{-1}$. The highest percentages of adhesion inhibition were obtained for $P$. aeruginosa (92\%), Staphylococcus aureus $(92 \%)$, Streptococcus oralis J22 (97\%) and Rothia dentocariosa GBJ (72\%), while low activity was obtained for Streptococcus mutans HG 985(50\%) and Staphylococcus epidermidis GB(22\%).

The antiadhesive activity of the crude biosurfactant isolated from C. sphaerica completely inhibited the adesion with a concentration of $10 \mathrm{mg} \mathrm{ml}^{-1}$ against Streptococcus agalactiae, Streptococcus mutans, Streptococcus mutans NS, Streptococcus sanguis 12, Streptococcus salivarius GB and Echerichia coli. These results were higher to that obtained with the biosurfactants isolated from Lact. paracasei ssp A20 [24]. A role of biosurfactants as defense weapons in competition with post-adhesion has been suggested for biosurfactants produced by Streptococcus mitis and S. mutans [39].

Besides possessing antifungal, antibacterial and antiviral activities, biosurfactants have also proved to be great inhibitors of microbial adhesion and of biofilm formation. For example, the biosurfactant released by $S$. mitis was found to reduce the adhesion of Streptococcus. mutans [40]. Similarly, Lactobacillus fermentum RC-14 releases surfactant compounds that can inhibit the adhesion of uropathogenic bacteria, including Enterococcus faecalis.

The adsorption of a biosurfactant on surface was found to change its hydrophobicity, which might caused interference in the adhesion and desorption processes [41]. Furthermore, Velraeds et al. [42] reported the inhibition of adhesion of pathogenic enteric bacteria by a biosurfactant produced by Lactobacillus fermetum RC-14. The authors suggested the use of this anti-adhesive agent in catheters aiming at decreasing biofilm formation. Falagas and Makris [37] have proposed the application of biosurfactants isolated from probiotic bacteria to patient care equipments (such as catheters and other medical insertional devices) in hospitals, with the aim of decreasing colonization by microorganisms responsible for nosocomial infections.

\section{Conclusion}

In conclusion, in this work we have demonstrated the antimicrobial and anti-adhesive properties of the crude biosurfactant isolated from C. lipolytica UCP0988 against several pathogenic and nonpathogenic microorganisms, including bacteria, yeasts and filamentous fungi. The results obtained suggest the possible use of this biosurfactant as an alternative 
antimicrobial agent in the medical field for applications against microorganisms responsible for diseases and infections, making it a suitable alternative to conventional antibiotics.

\section{Author details}

Raquel Diniz Rufino, Juliana Moura de Luna and Galba Maria de Campos-Takaki Nucleus for Research in Environmental Sciences and Center for Sciences and Technology, Catholic University of Pernambuco, Rua do Príncipe, Boa Vista, Recife- PE, Brazil

Leonie Asfora Sarubbo

Centre of Science and Technology, Catholic University of Pernambuco, Boa Vista, Recife-Pernambuco, Brazil

Lígia Raquel Marona Rodrigues and José Antônio C. Teixeira IBB, Institute for Biotechnology and Bioengineering, Centre of Biological Engineering, University of Minho, Campus de Gualtar, Braga, Portugal

\section{Acknowledgement}

This work was financially supported by Coordenação de Aperfeiçoamento de Pessoal de Nível Superior (CAPES), Fundação de Amparo à Ciência e Tecnologia do Estado de Pernambuco (FACEPE), Institute for Biotechnology and Bioengineering, Centre of Biological Engineering, Universidade do Minho, Braga, Portugal. We are grateful to Núcleo de Pesquisas em Ciências Ambientais (NPCIAMB) laboratories, Universidade Católica de Pernambuco, Brazil.

\section{References}

[1] Rufino RD, Sarubbo LA, Barros-Neto B, Campos-takaki GM. Experimental design for the production of tensio-active agent by Candida lipolytica. Journal Industrial Microbiology and Biotechnology 2008; 35: 907-914.

[2] Luna JM, Rufino RD, Sarubbo LA, Rodrigues LRM, Teixeira JAC, Campos-Takaki GM. Evaluation Antimicrobial and Antiadhesive Properties of the Biosurfactant Lunasan Produced by Candida sphaerica UCP 0995. Current Microbiology 2011; 62: 1527-1534.

[3] Sarubbo LA, Farias CBB, Campos-Takaki GM. Co-utilization of canola oil and glucose on the production of a surfactant by Candida lipolytica. Current Microbiology 2007; 54: 68-73.

[4] Sobrinho HBS, Rufino RD, Luna JM, Salgueiro AA, Campos-takaki GM, Leite LFC, Sarubbo LA. Utilization of two agroindustrial by-products for the production of a surfactant by Candida sphaerica UCP0995. Process Biochemistry 2008; 912-917.

[5] Rahman KSM, Gakpe E. Production, characterization and applications of biosurfactants- Review. Biotechnology 2008; 7: 360-370.

[6] Benincasa M. Rhamnolipid produced from agroindustrial wastes enhances hydrocarbon biodegradation in soil. Curr Microbial 2007; 56: 445-449.

[7] Das P, Mukherjee S, Sen R. Antiadhesive action of a marine microbial surfactant. Colloids and Surfaces B: Biointerfaces 2009; 71: 183-186. 
[8] Rodrigues LR, Moldes A, Teixeira JA, Oliveira R. Kinetic study of fermentative biosurfactant production by Lactobacillus strains. Biochemical Engineering Journal 2006e; 28: 109-116.

[9] Rodrigues LR, Van Der Mei HC, Teixeira JA, Oliveira R. Influence of biosurfactants from probiotic bacteria on formation of biofilms on voice prostheses. Applied and Environmental Microbiology 2004b; 70: 4408 - 4410.

[10] Mireles JR, Toguchi A, Harshey RM. Salmonella enterica serovar Typhimurium swarming mutants with altered biofilm-forming abilities: surfactin inhibits biofilm formation. J Bacteriol 2001; 183: 5848-54.

[11] Boris S, Barbe's C. Role played by lactobacilli in controlling the population of vaginal pathogens. Microbes Infect. 2000; 2: 543-546.

[12] Singh P, Cameotra S Potential applications of microbial surfactants in biomedical sciences. Trends Biotechnol 2004; 22: 142-6.

[13] Rodrigues LR. Biosurfactants production by probiotic bacteria and inhibition of voice prostheses microbial colonization. PhD Thesis. Universidade do Minho; 2005.

[14] Kulakovskaya T, Kulakovskaya E, Golubev W. ATP leakage from yeast cells treated by extracellular glycolipids of Pseudozyma fusiformata. FEMS Yeast Res 2003; 3: 401-404.

[15] Reid G. In vitro testing of Lactobacillus acidophilus NCFM as a possible probiotic for the urogenital tract. Int Dairy 2000; 10: 415-419.

[16] Rufino RD, Luna JM, Sarubbo LA, Rodrigues LRM, Teixeira JAC, Campos-Takaki GM. Antimicrobial and anti-adhesive potential of a biosurfactant Rufisan produced by Candida lipolytica UCP 0988. Colloids and surfaces B: Biointerfaces 2011;84: 1-5.

[17] Golubev WI, Kulakovskaya TV, Golubeva W. The yeast Pseudozyma fusiformata VKM Y2821 producing an antifungal glycolipid. Microbiol 2001; 70: 553-556.

[18] Rodrigues LR, Teixeira JA, Van Der Mei HC, Oliveira R. Isolation and partial characterization of a biosurfactant produced by Streptococcus thermophilus A. Colloids and Surfaces B: Biointerfaces 2006a; 53: 105 -112.

[19] Dunne Jr WM. Bacterial adhesion: seen any good biofilms lately. Clin. Microbiol Rev 2002 15: 155-166.

[20] Ahimou F, Jacques P, Deleu M. Surfactin and iturin A effects on Bacillus subtilis surface hydrophobicity. Enzyme and Microbial Technology 2001; 27: 749-754.

[21] Abalos A, Pinazo A, Infante MR. Physicochemical and anti-microbial properties of new rhamnolipds produced by Pseudomonas aeruginosa AT10 from soybean oil refinery wastes. Langmuir 2001; 17: 1367-1371.

[22] Wright JR. Pulmonary surfactant: a front line of lung host defense. J Clin Invest 2003; 111: 1453-1455.

[23] Bai G, Brusseau ML, Miller RM. Influence of a rhamnolipid biosurfactant on the transport of bacteria through a sandy soil. Appl Environ Microbiol 1997; 63: 1866-1873.

[24] Gudiña EJ, Rocha V, Teixeira JA, Rodrigues LR. Antimicrobial and antiadhesive properties of a biosurfactant isolated from Lactobacillus paracasei SSP. Paracasei A20. Applied Microbiology 2010a; 50: 419-424.

[25] Fernandes A, Arruda IR, Santos AFAB, Araújo A, Maior AM, Ximenes EA. Antimicrobial activity of surfactants produced by Bacillus subtilis r14 against multidrugresistant bacteria Brazilian Journal of Microbiology 2007; 38: 704-709. 
[26] Gudiña EJ, Teixeira JA, Rodrigues LR. Isolation and functional characterization of a biosurfactant produced by Lactobacillus paracasei. Colloids and Surfaces B: Biointerfaces 2010; 76: 298-304.

[27] Rodrigues LR, Banat IM, Van Der Mei HC, Teixeira JA, Oliveira R Interference in adhesion of bacteria and yeasts isolated from explanted voice prostheses to silicone rubber by rhamnolipid biosurfactants. Journal of Applied Microbiology 2006 d; 100: 470-480.

[28] Elving GJ, Van Der Mei HC, Busscher HJ, Van Weissenbruch R, Albers FW. Comparision of the microbial composition of voice prosthesis biofilms from patients requiring frequent versus infrequent replacement. Annals of Otology, Rihinol Laryngol 2002; 111: 200-203.

[29] Calvo C, Manzanera M, Silva-Castro GA, González-Lopéz J. Application of bioemulsifiers in soil oil bioremediation processes. Future Prospects. Science of the Total Envrironment 2009; 407: 3634-3640.

[30] Carrilo C, Teruel JA, Aranda FJ, Ortiz A Molecular mechanism of membrane permeabilization by the peptide antibiotic surfactin. Biochimica et Biophysica Acta 2003; 1611: 91-97.

[31] Singh A, Van Hamme JD, Ward OP. Surfactants in microbiology and biotechnology: Part 2. Application aspects Biotechnol 2007; 25: 99-121.

[32] Elving GJ, Van Der Mei HC, Busscher HJ, Amerogen EC, Van Weissenbruch R, Albers FW. Antimicrobial activity of synthetic salivary peptides against voice prosthetic microorganisms Laryngoscope 2000; 110: 321-324.

[33] Lang S, Katsiwela E, Wagner F. Antimicrobial effects of biosurfactants. Fat Science Technology 1989; 9: 363-366.

[34] Kitamoto D, Isoda H, Nakahara T. Functions and potential applications of glycolipid biosurfactants - from energy-saving materials to gene delivery carriers. Journal of Bioscience and Bioengineering 2002; 94: 187-201.

[35] Busscher HJ, Van Hoogmoed CG, Geertsema-Doornbusch GI, Van Der Kuijl-Booij M, Van Der Mei HC Streptococcus thermophilus and its biosurfactants inhibit adhesion by Candida spp. On silicone rubber. Applied Environ Microbiol 1997; 63: 3810-3817.

[36] Nitschke M, Ferraz C, Pastore GM. Selection of microorganisms for biosurfactant production using agroindustrial wastes. Brazilian Journal of Microbiology 2004; 35: 336-341.

[37] Falagas MF, Makris GC. Probiotic bacteria and biosurfactants for nosocomial infection control: a hypothesis. Journal Hosp Infect 2009; 71: 301-306.

[38] Mireles JR, Toguchi A, Harshey RM. Salmonella enterica serovar Typhimurium swarming mutants with altered biofilm-forming abilities: surfactin inhibits biofilm formation. J Bacteriol 2001; 183: 5848-54.

[39] Busscher HJ, Van Hoogmoed CG, Geertsema-Doornbusch GI, Van Der Kuijl-Booij M, Van Der Mei HC. Streptococcus thermophilus and its biosurfactants inhibit adhesion by Candida spp. On silicone rubber. Applied Environ Microbiol 1997; 63: 3810-3817.

[40] Pratt- Terpstra IH, Busscher HJ. Microbial factors in a thermodynamic approach of oral streptococcal adhesion to solid substrata. Journal Colloid Interface Science 1989; 129: 568-574.

[41] Fischer W. Molecular analysis of lipid macroamphiphiles by hydrophobic interaction chromatography. Journal of Microbiological Methods 1996; 25: 129 -144.

[42] Velraeds M, Van Der Mei HC, Reid G. Interference in initial adhesion of uropathogenic bacteria and yeasts to silicone rubber by a Lactobacillus acidophilus biosurfactant. J Med Microbiol 1998; 47: 1081-1085. 